\title{
Sistem Informasi Sekolah Berbasis Komputasi Awan
}

\author{
Denny Hermawan ${ }^{1}$, Rifqi Dhiyaulhaq Sami Miru ${ }^{1}$, Mukhalif ${ }^{2}$ \\ ${ }^{1}$ Program Studi Teknik Informatika, Fakultas Sains dan Teknologi, Universitas Al-Azhar Indonesia, \\ Jl. Sisingamangaraja, Kebayoran Baru, Jakarta Selatan, 12110 \\ ${ }^{2}$ Madrasah Aliyah dan Madrasah Tsanawiyah, Pondok Pesantren Ummul Qura, Gang Pesantren, RT.1/RW.4, \\ Pd. Cabe Ilir, Pamulang, Kota Tangerang Selatan, 15418 \\ Penulis untuk Korespondensi/E-mail: denny@uai.ac.id
}

\begin{abstract}
Abstrak - Saat ini lembaga pendidikan dituntut berubah dengan cepat mengikuti perkembangan era digital. Pesatnya perkembangan Internet mendorong stakeholder yang sudah terbiasa menggunakan layanan secara online, menginginkan layanan yang sama dalam mengakses informasi akademik. Hal ini disadari betul oleh para pemilik maupun pengelola lembaga pendidikan, namun penyediaan layanan sistem informasi akademik sekolah seringkali terkendala karena memerlukan investasi yang besar untuk pengembangan sistem maupun pengadaan infrastruktur data center dan perawatannya. Penelitian ini bertujuan untuk mengembangkan sistem informasi akademik yang di-deploy pada komputasi awan dengan model layanan Software as a Service (SaaS). Model layanan ini memungkinkan sekolah memanfaatkan sistem tanpa harus melakukan pengembangan dan perawatan sistem serta berinvestasi data center sendiri. Sekolah cukup melakukan registrasi pada sistem dan melakukan kustomisasi peran dan hak pengguna, penyesuaian logo sekolah, tampilan header rapor, serta komponen yang ada pada mata pelajaran dari setiap sekolah sesuai dengan kebutuhan. Sistem ini dibangun menggunakan metode pengembangan perangkat lunak model waterfall yang meliputi analisa kebutuhan, perancangan, implementasi, dan pengujian. Sistem yang dirancang dapat melakukan kegiatan penilaian pada siswa menjadi lebih mudah, karena para guru dapat langsung menginput nilai serta mengatur komponen nilai yang dimiliki di tiap-tiap mata pelajaran.
\end{abstract}

Abstract - Today, educational institutions are required to change rapidly following the development of the digital era. The rapid development of the Internet encourages stakeholders who are used to using services online, wanting the same service in accessing academic information. This is well known by the owners and managers of educational institutions, but the provision of school academic information system services is often constrained because it requires a large investment in the development of systems and the procurement of data center infrastructure and maintenance. This study aims to develop academic information systems that are deployed on cloud computing with the Software as a Service (SaaS) service model. This service model allows schools to utilize the system without having to develop and maintain the system and invest in their own data center. Schools only need to register the system and customize user roles and rights, adjust school logos, display report, and components that exist on the subjects of each school as needed. This system was built using the waterfall model software development method which included needs analysis, design, implementation, and testing. The system that is designed to carry out assessment activities on students becomes easier, because the teachers can directly input the values and set the components of the values they have in each subject.

Keywords - Cloud Computing, School Information System, Software as a Service.

\section{PENDAHULUAN}

$\mathrm{P}$ esatnya perkembangan internet menuntut adanya transformasi digital di berbagai bidang, termasuk di lembaga pendidikan atau sekolah. Para orangtua serta stakeholder lainnya menuntut kemudahan dalam mengakses layanan dan informasi sekolah seperti nilai dan laporan kemajuan belajar siswa dengan cepat dan mudah seperti halnya layanan online lainnya. Berdasarkan survei yang dilakukan oleh We Are Social, per Januari 2018, secara global pengguna internet di seluruh dunia mencapai lebih dari 4 milyar, atau sama dengan 57\% dengan kenaikan sekitar 9\% per tahun, persentase 
yang tidak jauh berbeda di survei yang sama dengan jumlah pengguna internet di Indonesia [1]. Hal ini menunjukkan sudah lebih dari separuh penduduk dunia dan Indonesia yang aktif menggunakan internet.

Di sisi lain masih banyak sekolah yang melakukan pencatatan dan pengolahan nilai siswa secara manual. Hal ini menjadi kendala karena pengolahan nilai siswa memerlukan waktu yang tidak sedikit. Guru harus memasukan nilai dengan manual menggunakan spreadsheet yang telah disediakan kemudian mengkompilasikannya kembali dalam bentuk rapor siswa, sehingga orangtua tidak bisa mendapatkan laporan hasil belajar anaknya secara cepat dan online.

Dalam penyediaan layanan sistem informasi, sekolah mengalami kendala karena memerlukan investasi yang besar untuk membayar programmer dan pengembang sistem. Sekolah juga harus membangun data centre yang terdiri dari beberapa server dan membangun seluruh kebutuhan pendukungnya seperti backup power, backup data dan lain-lain yang memerlukan dana yang tidak sedikit

Komputasi awan dapat menjadi solusi permasalahan di atas karena dapat mengurangi biaya dalam berinvestasi perangkat keras dan perangkat lunak [2]. Teknologi ini menawarkan kolaborasi dan kemudahan bagi penggunanya [3]. Komputasi awan juga menyediakan fleksibilitas bagi pengguna untuk menggunakan sumber daya komputasi sesuai dengan kebutuhan [4].

Penelitian ini bertujuan untuk mengembangkan sistem informasi akademik yang di-deploy pada komputasi awan dengan model layanan Software as a Service (SaaS). Model layanan ini memungkinkan sekolah memanfaatkan sistem tanpa harus melakukan pengembangan dan perawatan sistem serta berinvestasi data center sendiri [5]. Sekolah cukup melakukan registrasi pada sistem dan melakukan kustomisasi peran dan hak pengguna, penyesuaian logo sekolah, tampilan header rapor, serta komponen yang ada pada mata pelajaran dari setiap sekolah sesuai dengan kebutuhan. Sistem ini juga dapat diakses online oleh guru, tata usaha, wali kelas, siswa dan orangtua/wali murid kapan saja dan dimana saja dengan hak akses yang bisa dimodifikasi sesuai kebutuhan oleh admin sistem.

Sistem dikembangkan dengan metodologi System Development Life Cycle (SDLC) dengan model waterfall yang meliputi analisa kebutuhan, desain dan perancangan, implementasi, dan pengujian.

\section{METODE}

Pengembangan Sistem didesain menggunakan metode System Development Life Cyle (SDLC) dengan model waterfall yang dikembangkan oleh Winston Royce[6], meliputi analisis kebutuhan, perancangan sistem, implementasi, dan pengujian sistem.

Analisis kebutuhan sistem dilakukan dengan melakukan wawancara dan mempelajari sistem penilaian yang saat ini dijalankan di 2 buah lembaga pendidikan yakni: Yayasan Ummul Qura Pondok Cabe yang memiliki Madrasah Tsanawiyah dan Madrasah Aliyah, serta Yayasan Ummul Quro Depok yang memiliki Sekolah Dasar Islam Terpadu (SDIT) dan Sekolah Menengah Pertama Islam Terpadu (SMPIT). Kedua lembaga ini dipilih agar dapat menjadi sampel untuk pengembangan sistem agar dapat digunakan untuk tingkat Sekolah Dasar sampai Sekolah Menengah Pertama dan Madrasah Ibtidaiyah sampai Madrasah Aliyah. Analisis kebutuhan yang dilakukan meliputi pengolahan data siswa, mata pelajaran, jadwal pelajaran, tahun akademik, wali kelas, guru, tata usaha, rombongan belajar, nilai, sampai dengan laporan hasil belajar, serta analisis pengguna dan level otorisasi sistem.

Perancangan sistem yang akan dibangun meliputi perancangan fitur/modul, perancangan proses, struktur basisdata, perancangan antarmuka dan arsitektur sistem yang diperlukan untuk Komputasi Awan berbasis Software as a Service (SaaS).

Implementasi meliputi penulisan kode program sesuai dengan rancangan sistem yang telah didesain sebelumnya.

Pengujian fitur-fitur/modul sistem yang telah dikembangkan dan melakukan User Acceptance Test (UAT) dengan pengguna dari Yayasan Ummul Qura Pondok Cabe dan Yayasan Ummul Quro Depok.

Tahapan-tahapan tersebut di atas di dokumentasikan dan dikomunikasikan dengan pengguna menggunakan Unified Modeling Language (UML) yang merupakan bahasa standar untuk komunikasi dan desain perangkat lunak atau sistem informasi.[6] 
Lama pengembangan sistem dari mulai analisis kebutuhan sampai dengan pengujian dilakukan dalam waktu enam bulan dari mulai bulan Juli s.d. Desember 2018.

\section{HASIL DAN PEMBAHASAN}

\section{Analisis Kebutuhan}

Analisis kebutuhan dilakukan untuk mendapatkan gambaran kebutuhan apa saja yang diperlukan oleh pengguna dalam sistem yang akan dibangun.

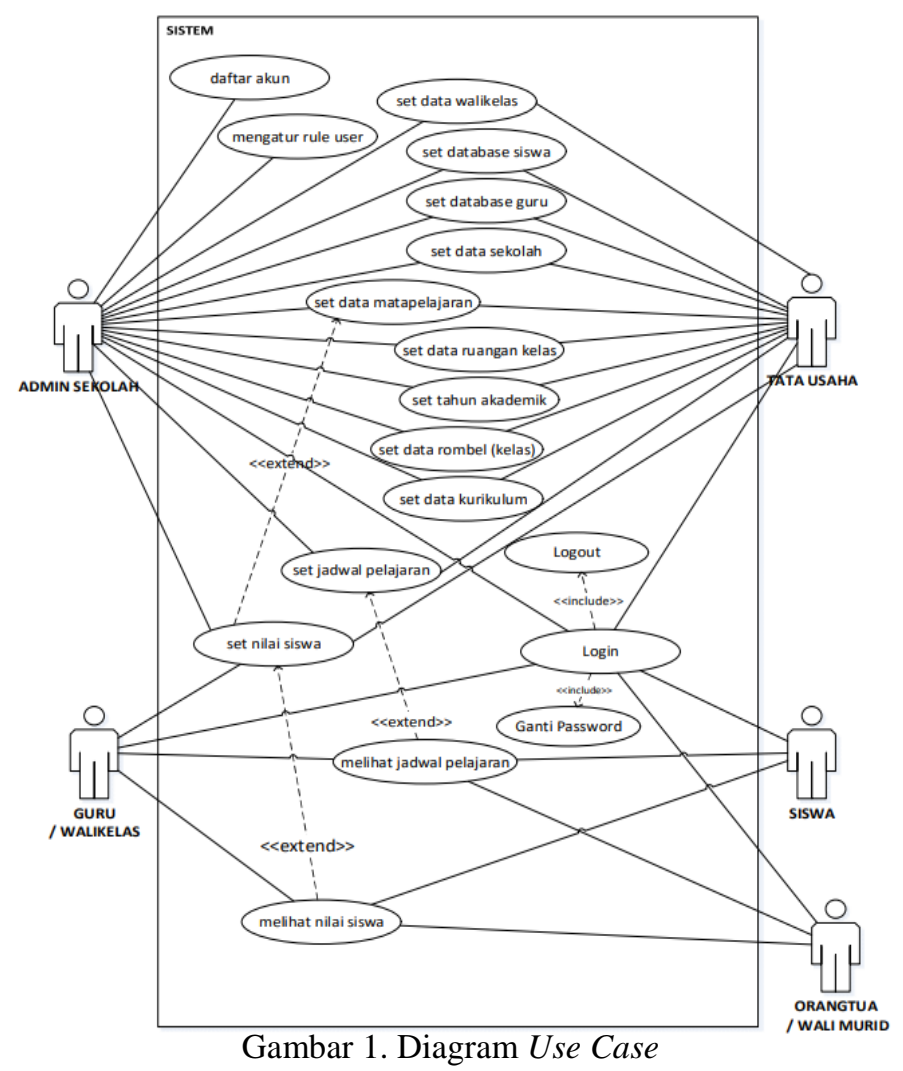

Sebagaimana terlihat pada Gambar 1., pengguna sistem terdiri dari Admin Sekolah, Tata Usaha, Guru/Wali Kelas, Siswa dan Orangtua/Wali Murid. Admin Sekolah adalah peran yang memegang semua hak akses fitur keseluruhan dan bertanggung jawab dalam mendaftarkan sekolah ke sistem dan membuat peran pengguna yang lain. Tata Usaha dan Admin dapat melakukan konfigurasi awal sistem sesuai kebutuhan sekolah dari mulai konfigurasi data siswa, guru, mata pelajaran, tahun akademik, kelas, kurikulum dan sebagainya. Dari Analisis Kebutuhan diketahui komponen penilaian pada sistem harus dapat diatur sesuai kebutuhan kurikulum 2013 yang memiliki 4 aspek penilaian, yaitu aspek pengetahuan, aspek keterampilan, aspek sikap, dan perilaku

\section{Perancangan Sistem}

Hasil analisis kebutuhan mendapatkan 18 fitur/modul, dari kebutuhan fitur tersebut dilakukan perancangan basis data. Sistem akan digunakan oleh banyak sekolah, dan dari setiap sekolah terdiri dari 5 peran pengguna yakni Admin Sekolah, Tata Usaha, Guru/Wali Kelas, Siswa, dan Orangtua Siswa. Untuk memenuhi kebutuhan tersebut dirancang basisdata yang digambarkan menjadi Diagram Logical Record Structures pada Gambar 2 dan Class Diagram pada Gambar 3.

Tabel yang dirancang untuk memenuhi kebutuhan sistem sebanyak 17 tabel yang akan digunakan untuk menyimpan data sekolah, data siswa, data guru, data tata usaha, kelas, ruangan, wali kelas, tahun akademik, history kelas, jadwal, mata pelajaran, orang tua, nilai, dan komponen nilai. Setiap orangtua dapat terhubung dengan banyak siswa di dalam satu sekolah untuk menyimpan data orangtua yang memiliki anak lebih dari satu pada sekolah yang sama.

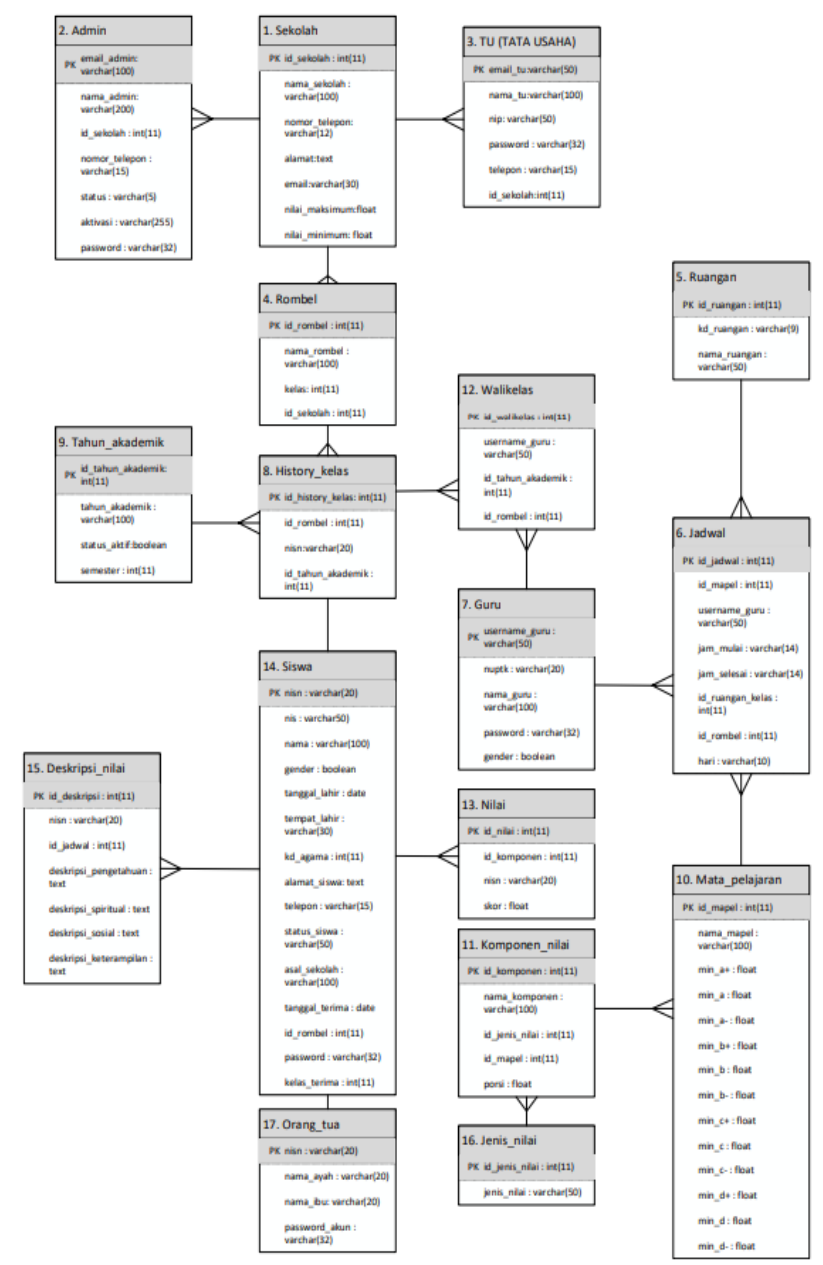

Gambar 2. Logical Record Structures 


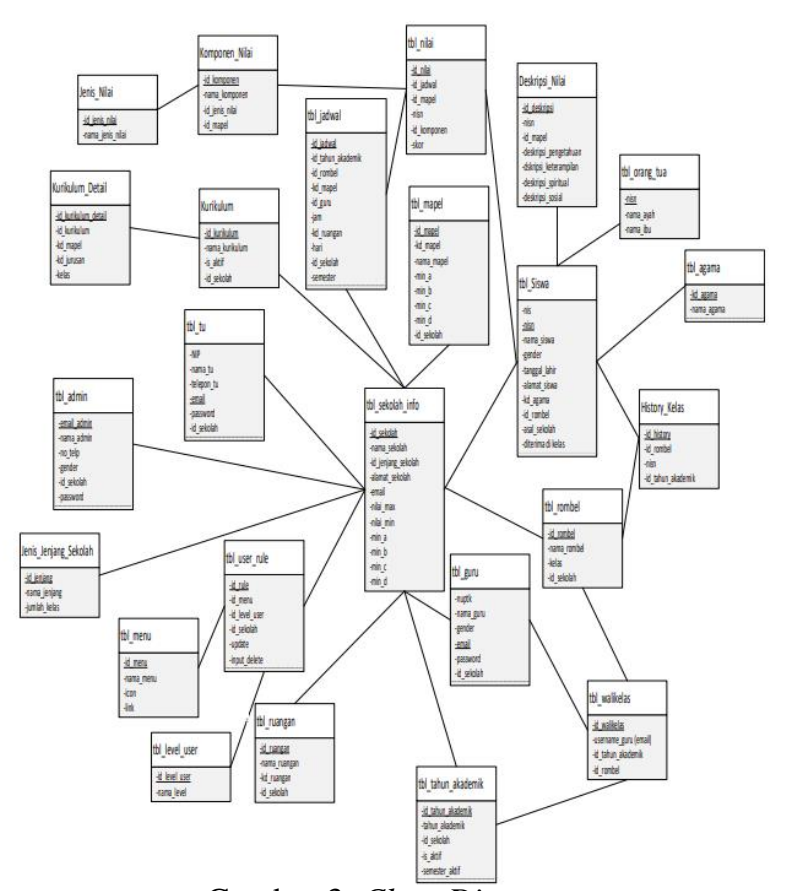

Gambar 3. Class Diagram

\section{Implementasi}

Sistem dibangun menggunakan arsitektur clientserver dengan menggunakan bahasa pemrograman PHP dengan konsep Model View Controller (MVC) [8]. Framework yang digunakan adalah CodeIgniter (CI). Framework CI digunakan karena memudahkan dalam proses perawatan atau maintenance sistem [9].

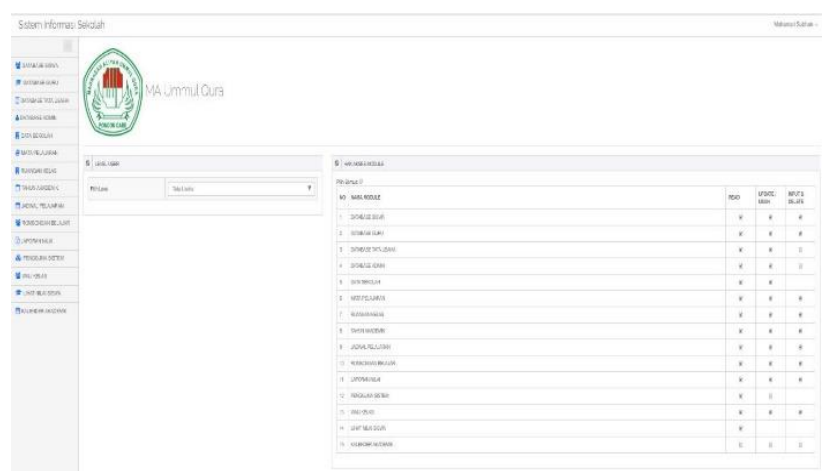

Gambar 4. Tampilan Pengaturan Hak Akses

Gambar 4. menunjukan implementasi tampilan pengaturan hak akses pengguna. Diperlukan pendaftaran sekolah terlebih dahulu ke sistem oleh Admin Sekolah, setelah terverifikasi dapat dilakukan pengaturan sekolah yang pembuatan dan pengaturan hak akses pengguna, tampilan sistem dan laporan, komponen nilai dan lain sebagainya sesuai dengan kebutuhan sekolah masing-masing.
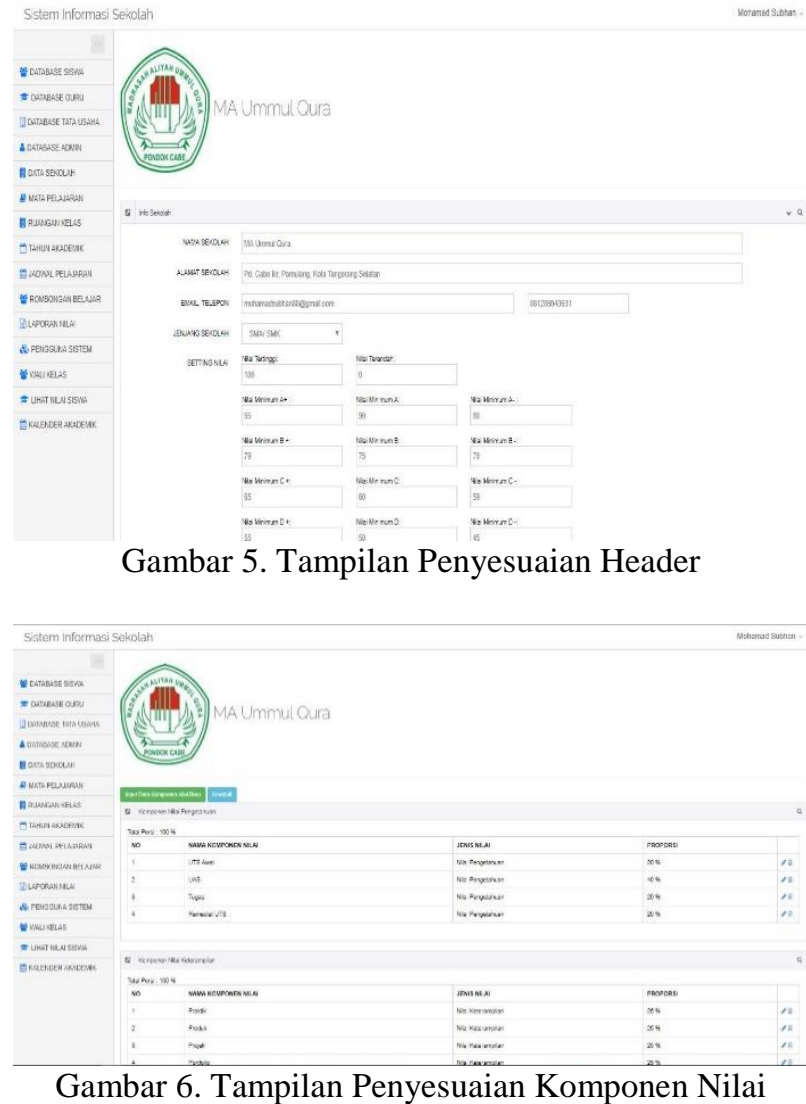

Gambar 6. Tampilan Penyesuaian Komponen Nilai

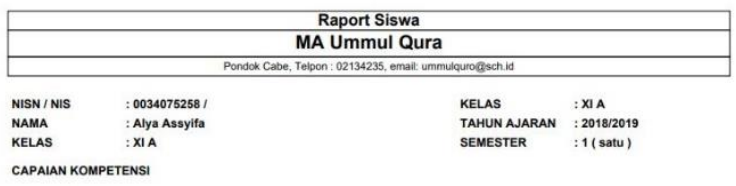

Gambar 7. Tampilan Header Laporan Belajar Siswa Menyesuaikan dengan Identitas Sekolah

\section{Pengujian}

Pengujian dilakukan kepada pengguna sistem dari semua peran pengguna yakni Admin Sekolah, Tata Usaha, Guru/Wali Kelas, Siswa, dan Orangtua Siswa. Pengujian dilakukan dengan metode blackbox testing. Metode pengujian ini menganalisis fungsi tertentu tanpa melihat struktur kode internal perangkat lunak. [10].

Hasil pengujian didokumentasikan dalam dokumen User Acceptance Test (UAT) yang memuat dan menguji fungsionalitas fitur-fitur yang diperlukan oleh pengguna sesuai dengan tahap analisis kebutuhan [11]. UAT yang dilakukan menghasilkan semua fitur sudah diterima dan sudah memenuhi kebutuhan yang diperlukan oleh pengguna sesuai dengan analisis kebutuhan di awal pengembangan sistem. 


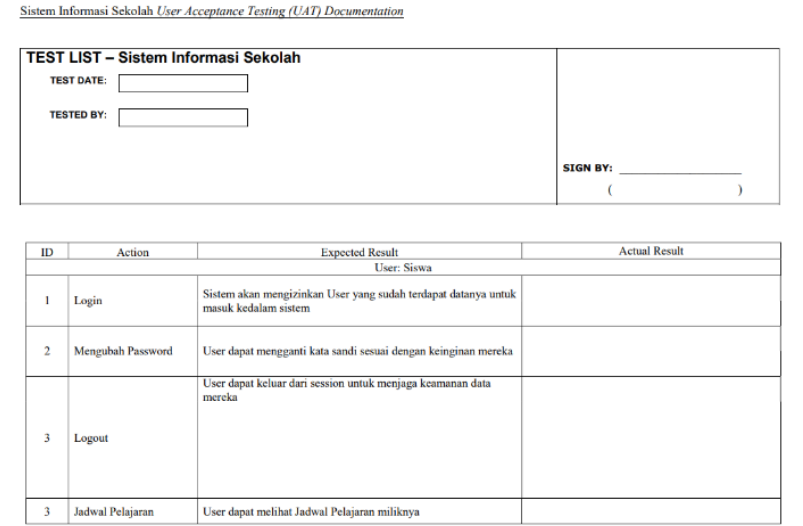

Gambar 8. Dokumen User Acceptance Test (UAT)

\section{KESIMPULAN}

Sistem Informasi Sekolah telah dikembangkan berbasis komputasi awan. Penerapan model layanan Software as a Service (SaaS) pada sistem ini memungkinkan sekolah dari mulai setingkat SD s.d SMA langsung dapat menggunakan sistem ini tanpa perlu menyediakan infrastruktur server dan data center sendiri dan dapat melakukan pengaturan secara fleksibel sesuai kebutuhan. Sistem dapat digunakan oleh banyak sekolah sekaligus dengan pengaturan masing-masing. Sistem dapat mengelola kegiatan akademik meliputi pengolahan data siswa, mata pelajaran, jadwal pelajaran, tahun akademik, wali kelas, guru, tata usaha, rombongan belajar, nilai, sampai dengan laporan hasil belajar. Sistem sudah mengakomodasi pengolahan nilai berbasis kurikulum 2013. Pengguna sistem terdiri dari Admin Sekolah, Tata Usaha, Guru/Wali Kelas, Siswa dan Orangtua/Wali Murid dan dapat diakses secara online kapan saja dan dimana saja.

\section{UCAPAN TERIMA KASIH}

Terima kasih kepada Pengurus Yayasan Ummul Quro Pondok Cabe dan Pengurus Yayasan Ummul Quro Depok, Kepala Sekolah SDIT, SMPIT, Madrasah Tsanawiyah dan Madrasah Aliyah yang telah memberikan izin dalam penggunaan data siswa, guru, mata pelajaran, rapor, dan juga data lainnya yang berguna pada sistem informasi sekolah yang dibangun.

\section{REFERENSI}

[1] We Are Social. Ltd, "Digital Report 2019"., https://wearesocial.com/uk/digital-2019, We Are Social. Ltd, 2019 (Diakses pada 1 Februari 2019)

[2] T. M. Grance, "The nist definition of cloud computing. Technical Report 800-145", National Institute of Standards and Technology (NIST), Gaithersburg, MD. 2011.

[3] Bojanova, and A.Samba, "Analysis of cloud computing delivery architecture models" In Proceedings of the 2011 IEEE Workshops of International Conference on Advanced Information Networking and Applications, WAINA '11, pages 453-458, Washington, DC, USA. IEEE Computer Society. 2011.

[4] D. W. Hofmann, "Cloud computing: The limits of public clouds for business applications", Internet Computing, IEEE, 14(6):90-93. 2010.

[5] A. S. Rumale and D. N. Chaudhari, "Cloud computing: Software as a service," 2017 Second International Conference on Electrical, Computer and Communication Technologies (ICECCT), Coimbatore, 2017, pp. 1-6.

[6] R. Pressman, "Software Engineering: a Practitioner's Approach, Fith Edition, “, McGraw-Hill Companies, Inc. 2001.

[7] J. Rumbaugh, I. Jacobson, and G. Booc. "Unified Modeling Language Reference Manual, the (2nd Edition)", Pearson Higher Education, 2004.

[8] J. Deacon. Model-View-Controller (MVC) Architecture, 10.1007/978-1-4302-5251-1_4. 1999.

[9] A. Griffiths, CodeIgniter 1.7 Professional Development. Birmingham, B27 6PA, UK. 2010.

[10] B. Beizer, "Black-Box Testing: Techniques for Functional Testing of Software and Systems", John Wiley \& Sons, Inc, New York, 1995.

[11] H. K. N. Leung and P. W. L. Wong, "A study of user acceptance tests. Software Quality Control", Journal Software Quality, Vol. 6. Issue 2, Pp. 137-149, 10.1023/A:1018503800709, 1997. 